\title{
SPATIAL ARRANGEMENT OF ODOR SOURCES MODIFIES THE TEMPORAL ASPECTS OF CRAYFISH SEARCH STRATEGIES
}

\author{
MARY C. WOLF, ${ }^{1,2}$ RAINER VOIGT, ${ }^{1}$ and PAUL A. MOORE ${ }^{1,2, *}$ \\ ${ }^{1}$ J. P. Scott Center for Neuroscience, Mind and Behavior Laboratory for Sensory Ecology, Department \\ of Biological Sciences, Bowling Green State University, Bowling Green, Ohio 43403, USA \\ ${ }^{2}$ University of Michigan Biological Station, 9008 Biological Road Pellston, Michigan 49769, USA
}

(Received March 19, 2003; accepted November 10, 2003)

\begin{abstract}
In natural habitats, animals encounter cues from multiple odor sources that may impact foraging decisions. Previous work has focused on orientation behavior to one food odor source, and does not distinguish between mechanosensory and chemosensory guidance of orientation. The present study investigated how the spatial distribution of two food cues affects crayfish orientation behavior. Crayfish, Orconectes virilis, were presented with odor sources that were separated in an artificial stream. Orientation behavior was filmed from above and digitized at a rate of 1 frame per sec. Electrochemical recordings were taken to characterize the odor plume, and an acoustic doppler velocimeter was used to characterize the hydrodynamic structure of the artificial stream. Temporal changes in odor plume structure were seen as a result of the positioning of the odor sources. Changes in the intermittency of the odor pulses as well as concentration, rise time, and slope of the pulse were observed. Time series analysis showed that the lower frequency signals of the dual odor source were higher in energy than the single $1 \mathrm{X}$ or single $2 \mathrm{X}$ sources. Crayfish altered orientation strategies when presented with different spatial arrangements of food cues. In particular, the temporal aspects of the orientation pattern were most altered by the differences in odor presentations. Crayfish responded with faster walking speeds as a function of distance to the odor source and exhibited more consistent turning angles. This correlates with temporal changes in odor structure, and indicates that the temporal pattern of odor stimulation may be driving the temporal pattern of behavior.
\end{abstract}

Key Words-Orientation strategies, Orconectes virilis, hydrodynamics, odor plumes structure, temporal and spatial search strategies.

*To whom correspondence should be addressed. E-mail: pmoore@bgnet.bgsu.edu 


\section{INTRODUCTION}

Crayfish must distinguish between complex odor signals and respond appropriately to locate mates, find food and prey, avoid predators, and select a habitat (Bouwma and Hazlett, 2001; Keller et al., 2001; Tomba et al., 2001). Here, we define complexity as an increase in range of temporal or spatial fluctuations within an odor plume. This complexity challenges the abilities of organisms to extract the necessary information to locate the source of an odor signal (Hazlett, 1999; Keller et al., 2001; Tomba et al., 2001).

In aquatic systems, various strategies are employed to orient toward an odor source. Blue crabs are thought to use an odor-gated rheotaxis to orient toward an odor source, i.e., they use the flow of water as spatial information and the concentration differences within and on the edges of the plume as temporal information to guide their movements (Weissburg and Zimmer-Faust, 1993; Zimmer-Faust et al., 1995; Finelli et al., 2000). Lobsters seem to rely more on a chemotactic strategy, i.e., they use both the temporal and spatial components of an odor plume to orient (McLeese, 1973; Moore et al., 1991; Atema, 1996). Crayfish appear to use a chemotactic strategy that is guided by spatial information within the odor plume (Moore and Grills, 1999; Keller et al., 2001; Tomba et al., 2001; Kraus-Epley and Moore, 2002). Therefore, the spatial or temporal distribution of the odor signal is critical for orientation behavior.

The fine-scale structure of chemical signals is important for its perception by organisms in their environment (Mafra-Neto and Cardé, 1995; Finelli et al., 1999; Moore et al., 2000). Three major factors could influence the spatial and temporal distribution of chemical signals: 1 ) the rate of release of a signal (Zimmer et al., 1999), 2) the hydrodynamic characteristics of the environment (Westerberg, 1991), and 3 ) the spatial location of odor sources in the habitat (Westerberg, 1991; Keller et al., 2001). Changes in odor plume structure have a strong effect on the efficiency of organisms to orient toward an odor source (Weissburg and Zimmer-Faust, 1993; Moore and Grills, 1999). For example, increases in turbulence as well as changes in pulse rate of the chemical signal altered plume variables, such as concentration within the patches and intermittency between the patches (Westerberg, 1991; Moore et al., 1994; Zimmer et al., 1999; Finelli et al., 2000; Moore et al., 2000).

Orientation behavior in crayfish becomes more efficient with increase of complexity of the odor signal (Moore and Grills, 1999; Keller et al., 2001; Tomba et al., 2001). Crayfish walk faster and spend more time moving toward the odor source with a wider range of temporal fluctuations in odor plumes. Changes in the physical habitat, i.e., substrate of the stream, alter the complexity of odor signals (Moore et al., 2000), and the spatial distribution of sources can alter orientation behavior of crayfish (Keller et al., 2001). The present study attempts to elucidate how changes in spatial-temporal aspects of an odor signal due to odor source placement alter the spatial-temporal orientation behavior of crayfish. 


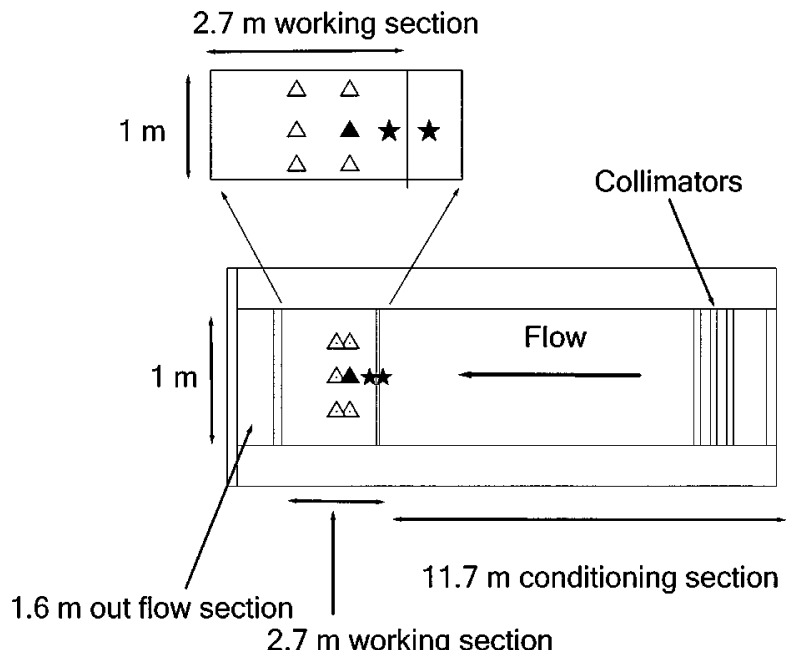

FIG. 1. Artificial stream setup at the UMBS Stream Research facility located in Pellston, MI. Water was pumped in continuously from the nearby Maple River. $\triangle-\mathrm{ADV}$ measurement sites, $\Delta-$ ADV and IVEC-10 measurement site, $\star$-Odor source placement. Width of the stream is projected four times its real width relative to the length. The inset shows the working section. Odor sources are $30 \mathrm{~cm}$ apart with the most upstream source behind the working section grating. The ADV recording sites were 1 and $1.3 \mathrm{~m}$ from the top of the working section and the IVEC sampling site is $40 \mathrm{~cm}$ from the odor source.

\section{METHODS AND MATERIALS}

Animals. Male and female Orconectes virilis were collected from Maple Bay in Burt Lake during the summer of 2001. Crayfish were housed in flowthrough outdoor metal troughs located at the University of Michigan Biological Station Stream Research Facility. They were allowed to acclimate to their new surroundings for at least $24 \mathrm{hr}$ and fed on detrital material that accumulated in the holding tanks. All crayfish were released after testing into Burt Lake, downstream of the capture site, to prevent recapture on subsequent sampling trips.

Artificial Stream Setup. An artificial stream $(16 \times 1 \times 0.2 \mathrm{~m})$ was constructed of concrete cinder blocks and 4-mm plastic sheeting (Figure 1). The plume was built to recognized standards in order to form an equilibrium benthic boundary layer (Nowell and Jumars, 1987). Stream water was used directly from the Maple River, resulting in a background concentration of natural odors that was consistent throughout all experimental trials. The stream contained an $11.7-\mathrm{m}$ flow conditioning section in front of the $2.7-\mathrm{m}$ working section and $1.6-\mathrm{m}$ outflow section. The water exited the artificial stream and re-entered the Maple River approximately 
200-m downstream of the intake for the stream lab. The end of the stream was covered with a $1.5 \times 0.35-\mathrm{m}$ board that contained $2.54-\mathrm{cm}$ diam holes evenly spaced throughout to maintain a constant depth and flow rate. Collimators consisting of three sheets of plastic egg crating $\left(1.7-\mathrm{cm}^{2}\right.$ holes) covered with fiberglass sheeting $\left(1-\mathrm{mm}^{2}\right.$ holes) were placed in the upper part of the stream to laminarize the incoming flow. The working section was partitioned off from the rest of the stream with two sheets of plastic egg crating spaced $2.7 \mathrm{~m}$ apart.

Water was pumped from the Maple River into a 1-m mixing area ahead of the 11.7-m stream section. In order to avoid excessive particulate matter buildup, the flow through pipes was equipped with nylon stockings secured to the ends of the flow pipe to filter out the fine organic matter and macroinvertebrate fauna.

Free stream velocity $(5.0 \pm 0.3 \mathrm{~cm} / \mathrm{sec})$ was measured at the beginning of each day by a Marsh-McBirney flow meter. Depth measurements ensured a uniform water depth of $20 \pm 0.3 \mathrm{~cm}$. The bottom of the stream was lined with cobble stones $(4.5 \pm 0.2 \mathrm{~cm}, N=24)$ collected from the Maple River. To facilitate orientation responses of animals, the entire working section of the artificial stream was covered with tarps to reduce ambient light conditions.

Hydrodynamic Characteristics. The hydrodynamic characteristics of the artificial stream were determined by measuring the instream flow with an acoustic doppler velocimeter (ADV, Nortek USA). Measurements were taken at two downstream positions $(1.1$ and $1.3 \mathrm{~m})$ within the working section of the stream. At each downstream position, three cross-stream sites and 2 depths were measured. The cross-stream sites were $51 \mathrm{~cm}$ from the right wall (midpoint of the stream) and $25 \mathrm{~cm}$ to the right and left of center of the stream (Figure 1).

For each of the vertical measurements, the probe tip was suspended at $5.9 \mathrm{~cm}$ and $6.5 \mathrm{~cm}$ above the substrate. The probe of the ADV was activated to determine the exact height above the substrate and then adjusted to the desired height. At each of the six sites ( 2 downstream $\times 3$ cross-stream each at 2 heights), threedimensional flow velocities were taken for $180 \mathrm{sec}$ at a sampling rate of $25 \mathrm{~Hz}$. Velocity profiles and calculation of hydrodynamic variables were performed offline (Explore package, Nortek).

Stimulus Preparation. Fish gelatin blocks were used to simulate the effect of slowly diffusing carrion odors, which crayfish feed on in natural systems. Fish gelatin was prepared by mixing $45 \mathrm{~g}$ of homogenized frozen ocean perch (Perca sp.) fillets with $28 \mathrm{~g}$ of Knox unflavored gelatin and 0.711 of boiling water. After mixing, the hot gelatin was placed in a baking pan lined with plastic wrap and refrigerated overnight until solidified. Solidified gelatin was cut into $3 \times 3 \times 1.5$-cm cubes. Gelatin blocks were quartered before each trial to allow for a uniform surface area, and placed in mesh bags (1- $\mathrm{mm}^{2}$ holes) with weights attached to the bottom to keep them in place during trials. As controls, empty mesh bags were placed in the same configuration as the bags containing the gelatin blocks. 
Orientation Trials. Four male and 36 female $O$. virilis were used only once in orientation trials. Previous studies have shown that there are no differences in orientation strategies between male and female crayfish (Moore and Grills, 1999; Keller et al., 2001; Tomba et al., 2001). Crayfish were marked with reflective tape on the back of the carapace and placed inside the stream for a 20 min acclimation period. Reflective tape facilitated observations of animals in subsequent motion analysis. Following a 20-min acclimation period, the mesh bags containing the fish gelatin blocks were placed in an upstream position, $15 \mathrm{~cm}$ from the top grating. Bags were also marked with reflective tape to allow for visual confirmation of the crayfish finding the source. Trials were defined as successful when the crayfish came within $10 \mathrm{~cm}$ of the source or touched the bag itself. Trials in which the crayfish did not move, walked along the walls, or did not locate the source were discarded. Sixty crayfish were used in the experimental trials where 4 in the single $1 \mathrm{X}, 15$ in the single $2 \mathrm{X}$, and 11 in the dual presentations were discarded. Trials were run until the animal located the odor source for a maximum of $15 \mathrm{~min}$. Trials were conducted during the months of June and July 2001 between 0800 and 1700 hours at the University of Michigan Biological Station Stream Research Facility in Pellston, Michigan. All trials were videotaped from above using a Cannon XL1 3 CCD Digital Video Camcorder. Orientation trials consisted of three experimental treatments and one control treatment. 1) Single concentration; single spatial source: One piece of fish gelatin was placed in a mesh bag at a single location within the stream $(N=10)$. Hence referred to as single 1X. 2) Double concentration; single spatial source: Two pieces of fish gelatin were placed in a single mesh bag at a single location within the stream $(N=10)$. Hence referred to as single $2 \mathrm{X}$. 3) Double concentration; dual spatial source: Two pieces of fish gelatin were placed in two bags (one in each bag), one $30 \mathrm{~cm}$ behind the other in an upstream position. One bag was placed $15-\mathrm{cm}$ downstream of the working section grating, the other $15-\mathrm{cm}$ upstream behind the grating $(N=10)$. Hence referred to as a dual source. 4) Control treatments consisted of an empty mesh bag $(N=10)$. Crayfish were able to reach the more downstream source only, and were used only once in the behavioral experiments to avoid the influence of experience on orientation behavior.

Odor Characterization. To characterize the odor plume structure, gelatin was laced with a chemical tracer (0.1-M dopamine). Dopamine (3.4 g) was mixed with $7 \mathrm{~g}$ of Knox gelatin in $0.178 \mathrm{l}$ of boiling water. Dopamine gelatin was placed in a baking dish and refrigerated overnight to solidify. The solidified cubes $(3 \times 3 \times$ $1.5-\mathrm{cm})$ were quartered, placed in mesh bags, and placed into the stream in the same positions as the fish gelatin.

An electrochemical detection technique was used to characterize the effects of different spatial arrangements of the odor source. The temporal distribution of dopamine was sampled at a rate of $10 \mathrm{~Hz}$ using the In Vivo Electrochemistry Computer System (IVEC-10). Electrochemical measurements were made with a 
$30-\mu \mathrm{m}$ diameter carbon fiber electrode calibrated by using four concentrations of dopamine ranging from 0 to $30 \mu \mathrm{M}$. Electrodes were calibrated with the above concentration range in a 50-ml beaker. These concentrations were used only for calibration of the electrode. Electrode readings showed linearity over this range (coefficient of determination: $r^{2}>0.97$ ). Five-min electrochemical recordings that used 1-M dopamine gelatin were made $40 \mathrm{~cm}$ from the odor source with each source arrangement to measure the temporal and spatial distribution of the chemical double, hence food odor distribution (Figure 1).

Data Analysis. Flow data obtained through measurements by using the ADV system were analyzed by the commercial software program provided with the ADV system (Explore). Hydrodynamic characteristics were estimated from the data following standard practices (Sanford,1997). The turbulent energy dissipation rate was calculated from Eq. 1 below (Sanford, 1997):

$$
\varepsilon=\left(U^{3}\right) / \kappa z
$$

where $U$ is the free stream velocity, $\kappa$ is von Karman's constant $(0.41)$, and $z$ is the height above the stream bed.

From the values obtained, we were able to calculate the Kolmogorov microscale ( $\eta$, Eq. 2$)$ and the Batchelor microscale ( $\eta_{s}$, Eq. 3; Sanford, 1997). These microscales are the measurements of the smallest eddy sizes, Kolmogorov, and the smallest distances for differences in chemical concentrations, Batchelor.

$$
\begin{aligned}
\eta & =2 \pi\left(v^{3} / \varepsilon\right)^{1 / 4} \\
\eta_{s} & =2 \pi\left(v D_{s}^{2} / \varepsilon\right)^{1 / 4}
\end{aligned}
$$

The coefficient $D_{s}$ is the molecular diffusion coefficient of dopamine $(2 \times$ $10^{-5} \mathrm{~cm}^{2} / \mathrm{sec}$ ). A spectral analysis of the velocity values was performed using the ADV Explore program at a 95\% confidence level using Tukey HSD comparison test.

IVEC-10 data were analyzed by using an in-house basic program. Spatial and temporal components of the odor plume such as, maximum height of the odor pulse (highest concentration of chemical within the odor pulse), absolute slope (from threshold to highest concentration within an odor pulse/rise time), maximum slope (highest increase of concentration between two measurements), and rise time (from threshold to the highest value within an odor pulse), number of peaks (number of odor pulses in the entire trial), intermittency (time between peaks of two odor pulses), and spectral density (energy of the signal as a function of frequency) were measured for each arrangement of the odor sources. The beginning of odor pulses was determined as the concentration rose above a threshold, and the end was determined when the concentration dropped below $30 \%$ of the previous peak height (Moore and Atema, 1991). Values obtained were averaged for each spatial position and analyzed using a Kruskal-Wallis ANOVA by ranks test. Tests for normality of 
the data showed that they were not normally distributed. Spectral analysis of odor signals (FFT and spectral densities) was performed with a commercial statistical package (Statistica by Statsoft). For each odor source measurement, there were 3432 data points. These were subsequently divided into five subsamples for each of the odor arrangements. The subsequent subsamples were used in the spectral analysis for each odor placement (Moore et al., 2000). For statistical analysis only, the energy in these odor spectra were binned in $0.5-\mathrm{Hz}$ bins. A 2 -way factorial ANOVA, with odor arrangement and frequency bin as the factors, was performed with the five-subsample (686 data points each) spectra from each odor arrangement. A Tukey HSD post hoc test was used to determine individual differences. The resulting spectra from the five subsamples of each odor placement were averaged and plotted against frequency.

Videotaped trials were digitized 1 frame/sec by using the Peak Motus System to obtain X, Y spatial coordinates of crayfish movements throughout each trial. An array of behavioral parameters were analyzed including success rate, time to locate odor source, linearity of path, walking speed, walking speed toward source, heading angle, heading angle relative to source and relative to upstream, and turning angle. These are explained and defined in a previous publication (Moore and Grills, 1999). A detailed temporal analysis was performed on walking speeds, turning angles, and heading angles. These were analyzed statistically using a MANOVA and Fisher LSD post hoc test. The behavioral parameter of question (i.e., walking speed, turning angle, and heading angle) was averaged over a $10-\mathrm{cm}$ bin at different distances from the odor source for each individual animal. These individual binned averages were then used in either a 2nd (walking speed) or 3rd (turning angle) order polynomial regression analysis (Moore et al., 1991). Each of these regressions was statistically significant $(P<0.05)$. The coefficients for each of the individual regressions were averaged for the entire population and used to generate the population level regressions displayed on the figures in this manuscript. Only those animals that did not contact the side walls during any part of the orientation trial were included in the regression analysis. Following regression analysis, walking speeds were analyzed in blocks of distance from the odor source; $100-150 \mathrm{~cm}$, $50-100 \mathrm{~cm}$, and $0-50 \mathrm{~cm}$, by using a 2-way ANOVA and unequal $N$ HSD post hoc test.

\section{RESULTS}

Hydrodynamic Characterization. Measurement of the hydrodynamic structure of the artificial stream showed that the boundary layer was in equilibrium throughout the working section of the stream (Table 1). Spectral analysis of both the 1.1-m and 1.3-m sites at each vertical point indicated a uniform consistency of flow speed (Figure 2), i.e., the flow speed did not change significantly over the course of the working section. 
TABle 1. Hydrodynamic Characteristics of AN ARTIFiCIAL Stream ${ }^{a}$

\begin{tabular}{lcccc}
\hline Distance from top of working section & $U_{\infty}(\mathrm{cm} / \mathrm{s})$ & $\varepsilon\left(\mathrm{cm}^{2} / \mathrm{s}^{2}\right)$ & $\eta$ & $\eta_{\mathrm{s}}$ \\
\hline $1.1 \mathrm{~m}$ & 6 & 0.09 & $1.76 \mathrm{E}-05$ & $7.04 \mathrm{E}-11$ \\
$1.3 \mathrm{~m}$ & 6 & 0.09 & $1.79 \mathrm{E}-05$ & $7.17 \mathrm{E}-11$ \\
\hline
\end{tabular}

${ }^{a}$ Abbreviations: $U_{\infty}=$ free stream velocity, $\varepsilon=$ turbulent energy dissipation rate, $\eta=$ Kolmogorov scale, and $\eta_{\mathrm{s}}=$ Batchelor scale.
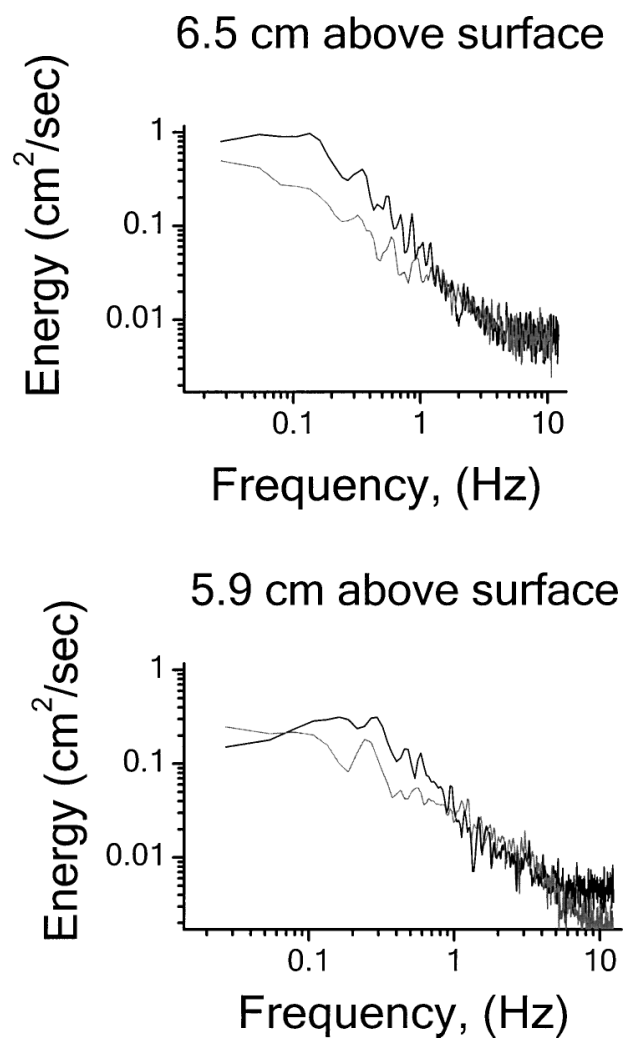

FIG. 2. Spectral analysis of water velocity in the artificial stream at two points within the working section of the stream. The solid black line represents measurements taken $1.1 \mathrm{~m}$ from the top of the working section and the light solid line represents measurements taken $1.3 \mathrm{~m}$ from the top of the working section. The vertical profile of the stream velocity at both distances shows the water velocity has reached equilibrium and that the boundary layer is $5.9 \mathrm{~cm}$ above the substrate. 


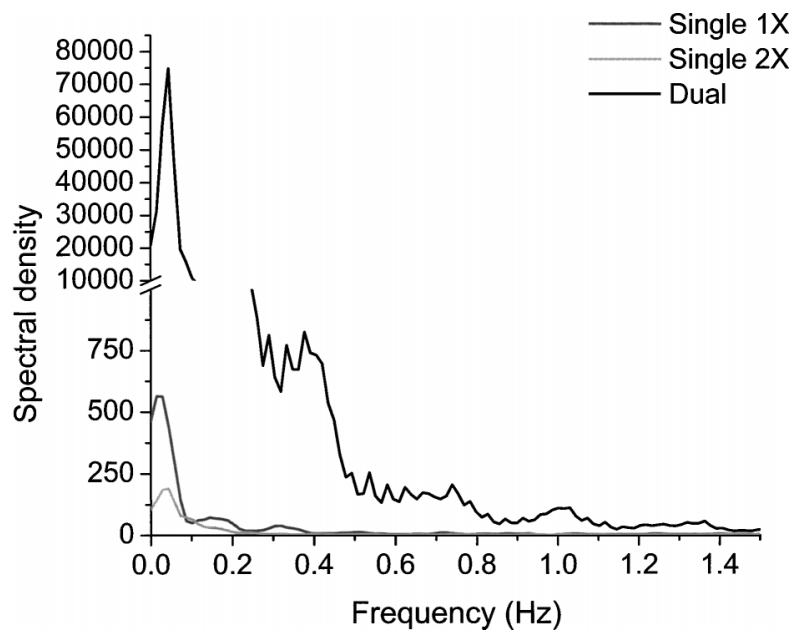

FIG. 3. Spectral analysis of the odor plume structure of the single $1 \mathrm{X}(N=1716)$, single $2 \mathrm{X}(N=1716)$, and dual $(N=1716)$ odor sources using $0.1 \mathrm{M}$ dopamine gelatin as an odor source. The light solid lines represent the single source arrangements and the black solid line represents the dual source arrangement.

Odor Characterization. Spectral analysis of the dual source arrangement with 1-M dopamine gelatin showed changes in the temporal patterns of the odor plume. The dual source arrangement exhibited a wide range of signal fluctuations across a wider range of frequencies (Figure 3). Analysis of the spectra of the different odor sources showed that there was an interaction between the placement of the odor sources and the frequency of the peaks (2-way ANOVA: $\left.F_{18}=14.9, P<0.001\right)$. Post hoc analysis showed that the dual source had more energy at the lower frequency peaks compared to the single $1 \mathrm{X}$ and single $2 \mathrm{X}$ sources (Tukey HSD: $P<0.001$ ). There were no differences between the single $1 \mathrm{X}$ and single $2 \mathrm{X}$ sources $(P=.99)$. Spectral analysis of both single source arrangements showed lower frequency signals $(<0.15 \mathrm{~Hz})$ with a steady decrease in signal energy as frequency increased. There was an overall difference in the intermittency of peaks within the three odor arrangements (Kruskal-Wallis: $\left.H_{2,1004}=90.91, P<0.05\right)$. Figure 4 shows that the intermittency between pulses was smaller for the dual source compared to the single $2 \mathrm{X}$ arrangement, but the single $1 \mathrm{X}$ arrangement had shorter intermittency than the other spatial arrays.

Table 2 shows additional changes in the odor plume structure as a result of altered spatial arrangement. The concentration or maximum height of the chemical tracer within each odor patch increased with the dual source arrangement (KruskalWallis: $\left.H_{2,1004}=55.72, P<0.05\right)$. The rise time decreased with the dual source arrangement (Kruskal-Wallis: $H_{2,1004}=19.1, P<0.05$ ). Additionally, 


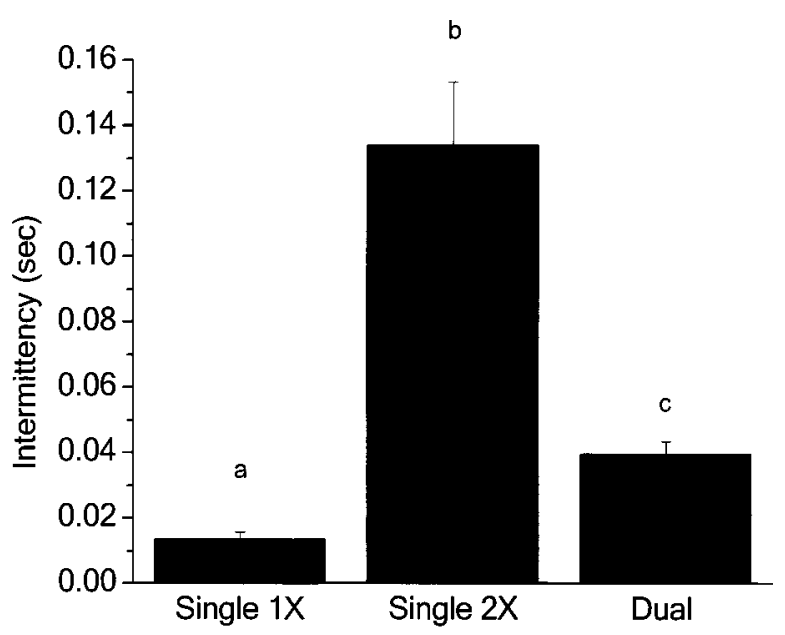

FIG. 4. Average time ( \pm SEM) between signal peaks (intermittency) of $0.1 \mathrm{M}$ dopamine gelatin. The dual odor source arrangement had less time between odor pulses than the single $2 \mathrm{X}$ source. Columns with the same letter are not significantly different from each other. Significant differences were determined by a Kruskal-Wallis ANOVA by ranks and multiple comparisons: single $1 \mathrm{X}(N=453)$ versus dual $(N=350)(Z=4.32, P<0.001)$, single $2 \mathrm{X}(N=200)$ versus dual $(Z=2.96, P<0.009)$.

the absolute slope (Kruskal-Wallis: $\left.H_{2,1004}=149.3, P<0.05\right)$ and maximum slope (Kruskal-Wallis: $H_{2,1004}=108.13, P<0.05$ ) of the odor patches increased as a result of the dual source.

Quantitative Analysis of the Temporal Aspects of Orientation Behavior. The temporal and spatial aspects of odor tracking behavior revealed differences in the strategies used to orient upstream. As crayfish moved upstream there was an overall effect of odor placement on spatial orientation (MANOVA: Rao's $R_{12,87}=$

TABle 2. Characterization Odor Plume

STRUCTURE OF SingLE $1 X$ AND SINGLE 2X AND

DuAl Odor SOURCE ARRANGEMENTS

\begin{tabular}{lrcr}
\hline & Single 1X & Single 2X & Dual \\
\hline Maximum height & 1.87 & 1.91 & $3.05^{*}$ \\
Absolute slope & 5.27 & 4.33 & $8.28^{*}$ \\
Maximum slope & 10.08 & 9.28 & $13.71^{*}$ \\
Rise time & 0.45 & 0.63 & $0.38^{*}$ \\
\hline
\end{tabular}

*Indicates significant differences (Kruskal-Wallis, $P<$ $0.001)$. Valid cases varied from 452 for single $1 \mathrm{X}, 200$ for single $2 \mathrm{X}$, and 350 for dual. 


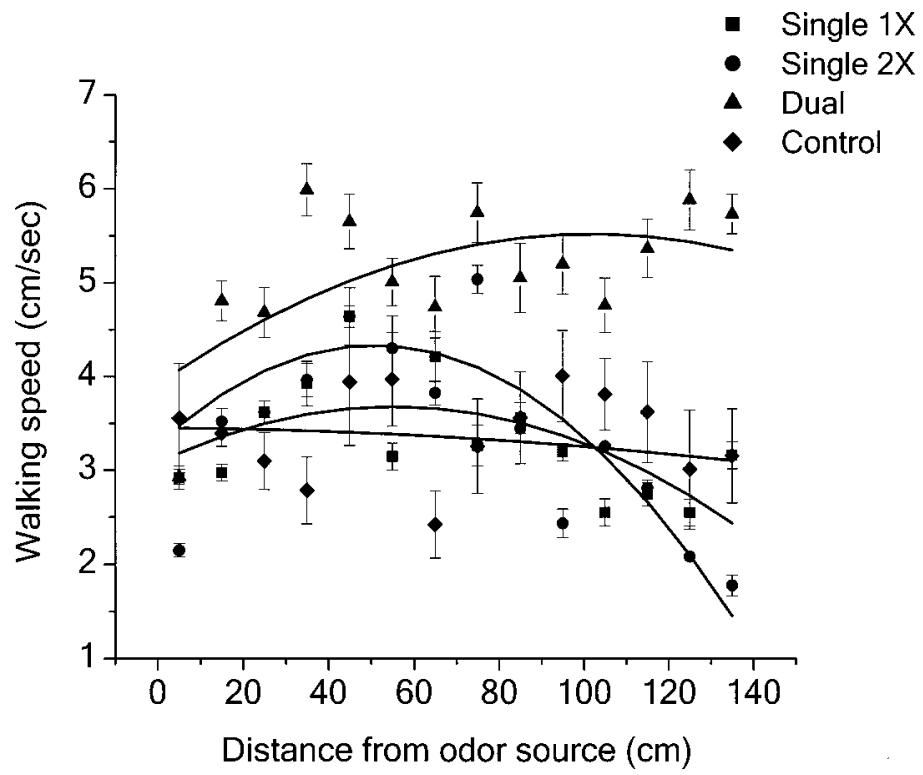

FIG. 5. Polynomial regression of walking speeds of crayfish as a function of distance to the

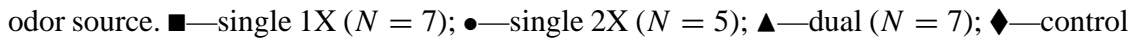
$(N=10)$.

2.83, $P<0.05)$. Turning angles of crayfish as they moved toward the source were smaller when presented with the dual source $(46.76 \pm 6.20$ degrees $)$ than control crayfish (67.01 \pm 6.71 degrees) (LSD: $P<0.05)$. Compared to the single $1 \mathrm{X}$ and single $2 \mathrm{X}$ source arrangements, there were no significant differences when crayfish were presented with the dual source (LSD: $P=0.16$ ). There were no differences between control crayfish and either single source arrangement (LSD: $P=0.65$ ). Crayfish presented with the empty bag controls did not locate the empty bags in the 15-min time frame allowed. As for the heading angle and the net-to-gross measurements, there were no differences between the odor placements.

Analyzing walking speeds and turning angles as a function of distance to the source revealed significant $(P<0.05)$ and different regressions for the different odor treatments. Walking speeds as a function of the distance to the source showed a three phase pattern. This general pattern was identical between the two single location odor sources (single $1 \mathrm{X}$ and single $2 \mathrm{X}$ source treatments). Under the dual odor treatment, the temporal aspects of orientation behavior were altered (Figure 5.). Crayfish presented with the dual source walked faster when they were 100-50 cm away compared to the single $1 \mathrm{X}$, single $2 \mathrm{X}$, or control presentation (HSD: $P<0.05$ ). As they approached the odor source, between $0-45 \mathrm{~cm}$, the differences in walking speeds under the three treatments were not maintained 


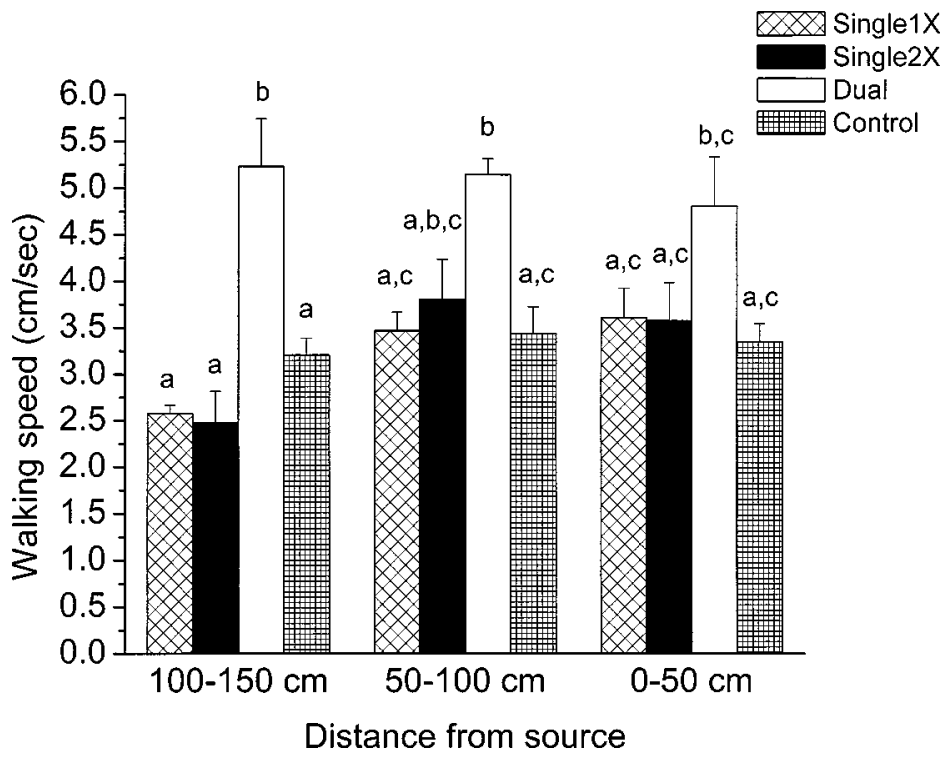

FIG. 6. Comparison of walking speeds of crayfish ( \pm SEM) when presented with the different odor placements in blocks of 50-cm distances from the odor source. $N=10$ for each treatment. Columns with the same letters are not significantly different from each other. A 2-way ANOVA for distance to the odor source and odor placement was performed $\left(F_{2,2}=31.5,4.0\right)$. Unequal $N$ HSD: $P<0.05$.

(Figure 6). This suggests that the placement, not the concentration, of the odor sources had an affect on temporal aspects of orientation behavior.

Turning angles of animals as a function of the distance to the source showed a similar result, in that animals started searching using identical turn angles far away from the source and then increased their turning angles sharply as they approached the source (Figure 7). Both single source arrangements showed a similar pattern in turn angles with relation to distance from the source, whereas the dual source arrangement had a much different pattern, particularly at a greater distance from the odor source (Figure 7). Turn angles of crayfish presented with the dual source were more constant as they moved upcurrent as opposed to the single source arrangements.

\section{DISCUSSION}

In order to understand how crayfish respond to complex signals we must know how those signals are distributed in a flowing environment. In the present study, IVEC measurements showed that spatially separated odor sources caused 


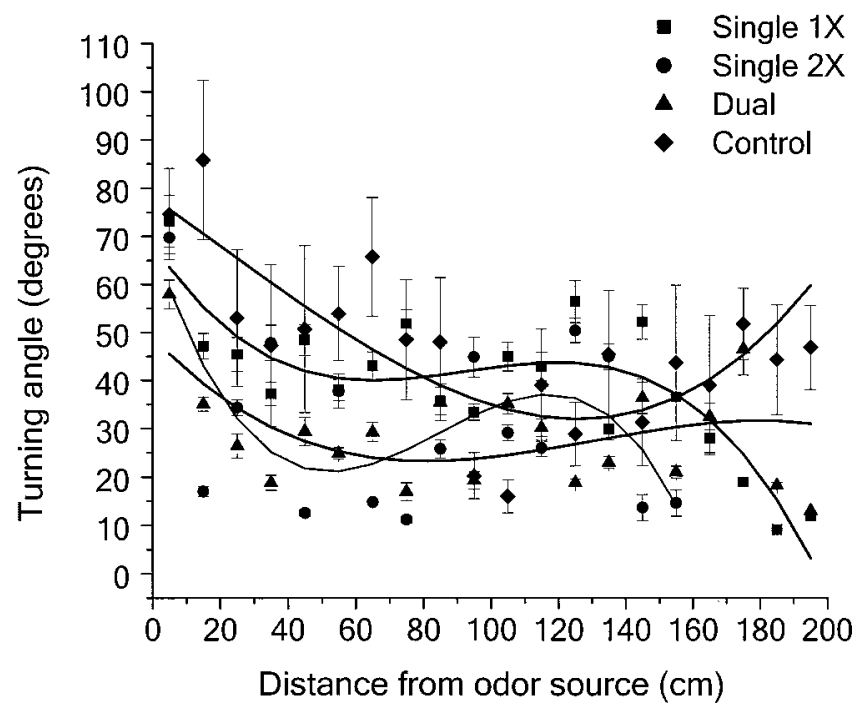

FIG. 7. Polynomial regression of turning angles of crayfish as a function of distance from the

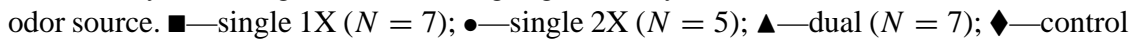
$(N=10)$.

the odor plume to have higher frequency components and more energy in the lower frequency components (Figure 3). We have defined the higher frequency components and increased energy as an increase in the "complexity" of the odor signals perceived by the crayfish during orientation. The spatial and temporal structure of the plume was more "complex" in the dual source arrangement compared to both single source arrangements. This "complexity" was further reflected in other temporal aspects of the odor signal such as mean peak height and intermittency (Table 2, Figure 8). The dual source arrangement presented crayfish with larger concentration fluctuations in shorter pulses than the single $2 \mathrm{X}$ source even though they were presented with similar surface area and concentration. The pattern in intermittency with the different spatial arrays showed that the single $1 \mathrm{X}$ source had more peaks and smaller intermittency between these peaks than either of the double sources.

Receptor cells of lobsters have been shown to act as temporal filters to extract spatial information from fluctuations in odor plumes (Gomez and Atema, 1999). These receptor cells vary in their temporal filtering capabilities, leading to differences in response to differing temporal fluctuations in odor plumes (Gomez et al., 1994; Gomez and Atema, 1996, 1999).

The behavioral data in the present study indicate the differences in the temporal complexity of the odor signal that resulted in more differences in the temporal 

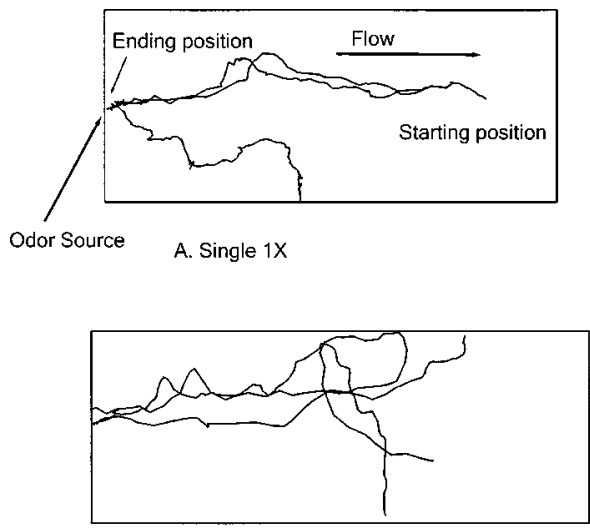

C. Dual

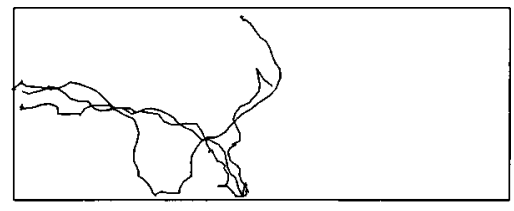

B. Single $2 x$

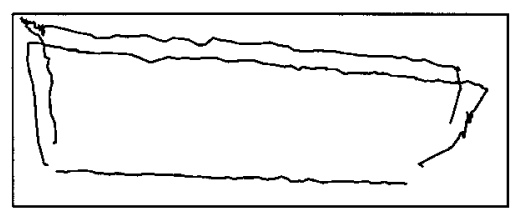

D. Control

FIG. 8. Representative orientation paths of three crayfish when presented with, A-single 1X, B-single 2X, C-dual, and D-control. Direction of flow, the relative position of the odor sources, and crayfish starting and ending positions are shown in A. Tracks were recorded $1 / \mathrm{sec}$.

aspects of orientation behavior (walking speed, and speed toward source) than the spatial aspects of orientation behavior (turning and heading angles). In general, crayfish located the odor source in all treatments. The paths of crayfish were similar to previously published studies and lacked any zig-zag patterns found in male moth orientation studies (Mafra-Neto and Cardé, 1996). In addition, orientation paths looked similar to those published for lobsters (McLeese, 1973; Moore et al., 1991). There were periods in the paths where animals stopped, moved sideways and backwards, as well as toward the odor source (Figure 5). Qualitatively, the orientation paths looked similar among the treatment groups. The orientation paths showed that animals exhibited a fairly straight course toward the source with a few corrections as they moved upcurrent.

By linking the IVEC results with the behavioral results, we show that the temporal dynamics of odor fluctuations were guiding upcurrent movement and turning behavior of crayfish. By altering the spatial arrangement of the odor sources we were able to alter temporal characteristics of the signal structure without altering the temporal dynamics of hydromechanical signals. Thus, changes seen in orientation strategies were a result of changes in the spatial arrangement of a food source as opposed to an increase in concentration of the individual food sources, or any alteration in mechanical information. None of the behavioral measurements quantified in this system were altered by changes in the concentration of the odor (single $2 \mathrm{X}$ vs. single $1 \mathrm{X}$ ). When one source was split and separated in space, crayfish maintained a faster walking speed and exhibited more consistent turning 
behavior as they moved upcurrent (Figures 5-7). In the current design, as crayfish reached approximately $50 \mathrm{~cm}$ from the odor source, turning angles increased sharply and walking speeds remained constant regardless of source placement. This change in behavior may indicate the point where animals switch to a local search strategy, possibly using more proximate cues, visual or tactile, to locate a close source. This general theme has been demonstrated in other studies with lobsters (Moore et al., 1991). As they approach a certain distance to the source a local search strategy takes over. The exact distance at which the local search occurs will change with changes in design paradigms, such as flow speed, turbulence, or concentration of the source.

Ecologically, aquatic organisms are faced with several problems that they must solve in order to perform life sustaining behaviors that are triggered by chemical information. In typical habitats, these animals experience multiple odor plumes that are mixing over a multitude of physical habitats (Finelli et al., 2000; Moore et al., 2000). Faced with this complexity, animals must not only recognize and distinguish predator from food, mate from food, or food from other odor signals, but also must be able to have some special awareness of these multiple odor sources, i.e., the ability to discriminate where these sources lie in relation to each other. With even a primitive ability to distinguish locations of odor sources relative to each other, animals will be able to make choices regarding foraging, avoiding predators, or mating. Studies with crayfish showed that they can effectively locate the spatial relationship of conflicting odor cues (Tomba et al., 2001). The results of the present study suggest that crayfish alter their behavioral output in response to increased temporal stimulation, which in turn, is a result of the changed spatial arrangement of food sources.

The way Crayfish orient toward an odor source is affected by changes in intermittency and intensity of the signal within each odor patch arriving at the antennules (Kozlowski et al., 2003). In studies with moths, the fine-scale structure, the flux of the stimulus, and the wind direction are all important in determining the response of males to female pheromones (Vickers and Baker, 1992, 1994; MafraNeto and Cardé, 1996). Changes in the rate of release and the fine-scale structure of the plume alter male flight characteristics in response to these changes (Murlis and Jones, 1981; Vickers and Baker, 1992) For blue crabs, the structure of the plume, as well as the direction of water flow, is important in orientation to odor sources (Zimmer-Faust et al., 1995; Finelli et al., 2000). This suggests that blue crabs orient by utilizing both the spatial and temporal aspects of an odor plume. Although it has been claimed that these animals are using an odor-gated rheotaxis, a recent model results make it hard to pinpoint an exact orientation mechanism for blue crabs (Weissburg and Dusenbery, 2002). Our findings lend support to the idea that temporal stimulation of the animal may play an important role in orientation behavior. We hypothesize that the presence or absence of the odor signal mediates movement toward the odor source. By altering the temporal and spatial dynamics 
of odor plumes we see changes in the temporal and spatial behavioral patterns of crayfish. Thus, we suggest that some spatial aspects of the odor plume are critical in changing the turning angles exhibited by crayfish during orientation behavior.

In summary, both the spatial and temporal aspects of orientation behavior in crayfish were altered by changes in odor plume dynamics. With an increase in the temporal complexity of odor signals, crayfish responded with higher walking speeds and smaller turning angles. By combining the chemical characteristics of the odor plume with hydrodynamic and behavioral measurements, we hypothesize that these crayfish were using a combination of the classically defined kinesis and taxis. Some aspects of crayfish orientation behavior can be termed a kinesis in that walking speeds were controlled by the stimulus distribution, while other aspects were similar to a taxis in that turning angles were decreased in the presence of increased temporal stimulation. It appears as if the crayfish in this study were not performing an odor-gated rheotaxis that has been reported for other benthic crustaceans (blue crabs, Weissburg and Zimmer-Faust, 1994).

Acknowledgments-The authors thank the UMBS for space and support for the use of the ADV system. This project was funded by a BGSU TIE grant and NSF AB-9874608 and IBN-0131320 to PAM.

\section{REFERENCES}

ATEMA, J. 1996. Eddy chemotaxis and odor landscapes: Exploration of nature with animal sensors. Biol. Bull. 191:129-138.

BOUWMA, P. and HAZLETT, B. A. 2001. Integration of multiple predator cues by the crayfish Orconectes propinqus. Anim. Behav. 61:771-776.

Finelli, C. M., Pentcheff, N. D., Zimmer-Faust, R. K., and Wethey, D. S. 1999. Odor transport in turbulent flows: Constraints on animal navigation. Limnol. Oceanogr. 44:1056-1071.

Finelli, C. M., Pentcheff, N. D., Zimmer, R. K., and Wethey, D. S. 2000. Physical constraints on ecological processes: A field test of odor-mediated foraging. Ecology 8:784-797.

GomeZ, G. and ATEMA, J. 1996. Temporal resolution in olfaction: Stimulus integration time of lobster chemoreceptor cells. J. Exp. Biol. 199:1771-1779.

GoMeZ, G. and ATEMA, J. 1999. Temporal resolution in olfaction III: Flicker fusion and concentrationdependent synchronization with stimulus pulse trains of antennular chemoreceptor cells in the American lobster. J. Comp. Physiol. A 185:427-436.

GoMeZ, G., VoIGT, R., and ATEMA, J. 1994. Frequency filter properties of lobster chemoreceptor cells determined with high-resolution stimulus measurement.J. Comp. Physiol. A 174:803-811.

HAZLETT, B. A. 1999. Response to multiple chemical cues by the crayfish Orconectes virilis. Behaviour 136:161-177.

Keller, T. A., TombA, A. M., and Moore, P. A. 2001. Orientation in complex chemical landscapes: Spatial arrangement of chemical sources influences crayfish food-finding efficiency in artificial streams. Limnol. Oceanogr. 46:238-247.

Kozlowski, C., Voigt, R., and Moore, P. A. 2003. Effect of pulsed odor sources on the tracking behavior of crayfish (Orconectes rusticus). Mar. Fresh. Behav. Physiol. 36:97-110.

Kraus-EPLeY, K. E. and MoORE, P. A. 2002. Bilateral and unilateral antennal lesions alter orientation abilities of the crayfish, Orconectes rusticus. Chem. Senses. 27:49-55. 
MAFRA-Neto, A. and CARDÉ, R. T. 1995. Influence of plume structure and pheromone concentration on upwind flight of Cadra cautella males. Physiol. Entomol. 20:117-133.

MAFrA-Neto, A. and CARDÉ, R. T. 1996. Dissection of the pheromone-modulated flight of moths using single-pulse response as a template. Experientia 52:373-379.

MCLEESE, D. W. 1973. Orientation of lobsters (Homarus americanus) to odor. J. Fish. Res. Board. Can. 30:838-840.

Moore, P. A. and ATEMA, J. 1991. Spatial information in the three-dimensional fine structure of an aquatic odor plume. Biol. Bull. 181:408-418.

MoOre, P. A. and GriLls, J. L. 1999. Chemical orientation to food by the crayfish Orconectes rusticus: Influence of hydrodynamics. Anim. Behav. 58:953-963.

Moore, P. A., Grills, J. L., and SchneIder, R. W. S. 2000. Habitat-specific signal structure for olfaction: An example from artificial streams. J. Chem. Ecol. 26:565-584.

MoORE, P. A., Scholz, N., and ATEMA, J. 1991. Chemical orientation of lobsters, Homarus americanus, in turbulent odor plumes. J. Chem. Ecol. 17:1293-1307.

Moore, P. A., Weissburg, M. J., Parrish, J. M., Zimmer-Faust, R. K., and Gerhardt, G. A. 1994. Spatial distribution of odors in simulated benthic boundary layer flows. J. Chem. Ecol. 20:225-279.

MuRLIS, J. and JONES, C. D. 1981. Fine-scale structure of odor plumes in relation to insect orientation to distant pheromone and other attractant sources. Physiol. Entomol. 6:71-86.

Nowell, A. R. M. and Jumars, P. A. 1987. Flumes: Theoretical and experimental considerations for simulation of benthic environments. Oceanogr. Mar. Biol. Ann. Rev. 25:91-112.

SANFORD, L. P. 1997. Turbulent mixing in experimental ecosystem studies. Mar. Ecol. Prog. Ser. 161:265-293.

TombA, A. M., Keller, T. A., and Moore, P. A. 2001. Foraging in complex odor landscapes: Chemical orientation strategies during stimulation by conflicting chemical cues. J. North. Am. Benthol. Soc. 20:211-222.

VICKERS, N. J. and BAKER, T. C. 1992. Male Heliothis virescens maintain upwind flight in response to experimentally pulsed filaments of their sex pheromone (Ledpidoptera: Noctuidae). J. Insect Behav. 5:669-687.

VICKERS, N. J. and BAKER, T. C. 1994. Reiterative responses to single strands of odor promote sustained upwind flight and odor source location by moths. Proc. Natl. Acad. Sci. U.S.A. 91:5756-5760.

WEISSBURG, M. J., and DUSENBERY, D. B. 2002. Behavioral observations and computer simulations of blue crab movement to a chemical source in a controlled turbulent flow. J. Exp. Biol. 205:33873398.

WeIssburg, M. J. and ZIMMER-FAust, R. K. 1993. Life and death in moving fluids: Hydrodynamic effects on chemosensory-mediated predation. Ecology 74:1428-1443.

Weissburg, M. J. and ZimmeR-FAust, R. K. 1994. Odor plumes and how blue crabs use them in finding prey. J. Exp. Biol. 197:349-375.

WeSTERBERG, H. 1991. Properties of aquatic odor trails, pp. 45-54, in K. B. Døving (ed.). Proceedings of the Tenth International Symposium on Olfaction and Taste. Graphic Communication System, Oslo.

Zimmer, R. K., Commins, J. E., and Browne, K. A. 1999. Regulatory effects of environmental chemical signals on search behavior and foraging success. Ecology 80:1432-1446.

Zimmer-Faust, R. K., Finelli, C. M., PentchefF, N. D., and Wethey, D. S. 1995. Odor plumes and animal navigation in turbulent water flow: A field study. Biol. Bull. 188:111-116. 